Article

\title{
A System-of-Systems Approach for Integrated Resilience Assessment in Highway Transportation Infrastructure Investment
}

\author{
Ali Mostafavi \\ Zachry Department of Civil Engineering, Texas A\&M University, College Station, TX 77843, USA; \\ amostafavi@civil.tamu.edu; Tel.: +1-979-845-4856
}

Received: 21 November 2017; Accepted: 8 December 2017; Published: 10 December 2017

\begin{abstract}
The objective of this paper is to propose a System-of-Systems (SoS) approach for an integrated assessment of resilience in civil transportation infrastructure in the U.S. A SoS approach is adopted for systemic assessment. Data obtained from case studies of two recent natural disasters in the U.S. are utilized to explore the status quo, key players and interactions, and the drivers to and barriers of improving resilience in transportation infrastructure systems. The findings indicate that strategies for enhancing resilience in transportation infrastructure systems include redistributing the available funding through a special funding vehicle, using resilience-based performance measures, and integrating the efforts of different stakeholders. The SoS approach along with the findings from the case studies provides an analytical tool for understanding the dynamics of resilience in infrastructure systems. Such understanding could lead to identifying strategies for enhancing resilience in infrastructure systems. The study presented in this paper provides new insights to identify the determinants of resilience in highway transportation infrastructure based on a SoS approach.
\end{abstract}

Keywords: resilience; infrastructure management; transportation infrastructure; System-of-Systems analysis; policy; infrastructure; funding; System-of-Systems

\section{Introduction}

The terms vulnerability and resilience have entered into the disaster literature in the last three decades. Kenneth Hewitt used the term "vulnerability" in the 1980s in his seminal book, "Interpretations of Calamity" [1]. He criticized the then dominant view in the disaster literature that considered disasters as unexpected acts of nature that were beyond the control of human beings. He echoed White's [2] view that "floods are 'acts of God', but flood losses are largely acts of man" (p. 2). According to Hewitt, disasters are neither natural nor unexpected events. They disproportionately affect certain groups, such as the poor. In that sense, disasters are expressions of "vulnerability," whose sources (e.g., poverty in case of the poor) lie within our everyday lives. Holling [3] was the first person to introduce the concept of "resilience" in the context of ecological systems, referring to the ability of an ecosystem to absorb changes and persist. There are three broad conceptualizations of resilience: (a) the ability of people to cope with and "bounce back" from disasters ([4-6]); (b) the ability of places to withstand and recover from a hazard in a relatively speedy manner without major disruption ([7-9]) and without extensive assistance from outside [10]; and (c) the capacity of communities to anticipate, prepare for, respond to and recover in a rapid manner from a disaster [11].

Infrastructure systems are recognized as a key element in investigating the vulnerability and resilience of communities in the context of disasters [12]. Accordingly, infrastructure resilience is defined as the ability of an infrastructure asset to maintain its performance to serve the required functions before, during, and after the occurrence of a natural hazard. The ability of infrastructure 
systems to cope with future uncertain conditions (e.g., hurricanes, earthquakes, and population growth/decline) has diminished due to the significant disparity between the supply and demand for financial, human, environmental, and physical resources. Traditionally, infrastructure planning decisions (e.g., financing, resource allocation, maintenance and rehabilitation, and capacity expansion) have been made in the following ways: (i) assets are each considered individually, not as part of the system in which they function [13]; (ii) feasibility is mainly based on economic criteria, such as cost-benefit analysis; and (iii) without the consideration of the impacts that an asset's condition has on its level of resilience against natural disasters [14]. The resilience of an infrastructure system depends on the condition of its assets; and the condition of its assets are affected by the activities and interactions of different players on both the supply and demand sides of infrastructure systems. On the supply side, the decision-making processes of different players affect the level of funding available for infrastructure development; and on the demand side, the decision-making processes of different players affect the decision-making process through which infrastructure projects are prioritized for rehabilitation, capacity expansion, and retrofit actions within the existing budget constraints. Therefore, the decision to rehabilitate, expand capacity, or perform retrofit projects, or the decision not to, directly affects the condition of the assets. This impacts the assets' performance (e.g., coping capacity, flexibility, and preparedness), which ultimately affects the resilience of infrastructure systems [15].

In the context of infrastructure systems, several studies (e.g., [16-18]) evaluated the ability to cope with natural disasters using the principles of resilience analysis. However, the existing studies have three limitations: (1) they focus on a single level of analysis (mainly the network level); (2) they focus on the demand side of the problem pertaining to infrastructure resilience; and (3) the existing condition of the infrastructure and the decision-making processes of the players pertaining to planning and resource allocation were not considered. There is a knowledge gap related to investigating the link between the decision-making processes of different players pertaining to resource allocation for rehabilitation, capacity expansion, and retrofit actions; the condition of infrastructure assets; and the level of resilience of infrastructure systems against natural disasters at the asset, network, sub-national, and national levels. The objective of this paper is to propose a SoS approach for integrated assessment of resilience in infrastructure systems. The proposed approach is then used for assessment of the dynamics of transportation infrastructure resilience in the U.S. using the information collected from two case studies of 2012 Hurricane Sandy and 2013 Colorado Floods.

\subsection{System-of-System Approach}

The first step in systems analysis is to determine the type of the system (e.g., monolithic vs. systems, or system-of-systems (SoS). Different types of systems have different traits. The traits of an SoS are presented in this section in order to determine whether infrastructure resilience can be characterized as an SoS problem. Rechtin defines a monolithic system as a set of different elements so connected or related so as to perform a unique function not performable by the elements alone. Along the same lines, DeLaurentis [19] characterize a SoS as "the combination of a set of different systems [that] forms a larger system of systems that performs a function not performable by a single system alone" Maier [20] defines a SoS as "an assemblage of components which individually may be regarded as systems, and which possesses two additional properties: operational independence of components...and managerial independence of the components". SoSs have different traits than monolithic systems. Civil infrastructure is a SoS due to the existence and interaction of several independent/interdependent systems and players whose interactions affect resilience (Figure 1). As shown in Figure 1, the complex relationships among various human actors and their decision-making processes in response to the evolving hazards landscape affect the resilience performance of infrastructure systems. Hence, the creation of a SoS approach provides a better theoretical lens and facilitates a bottom-up assessment of coupled human-infrastructure systems ([21-23]). 


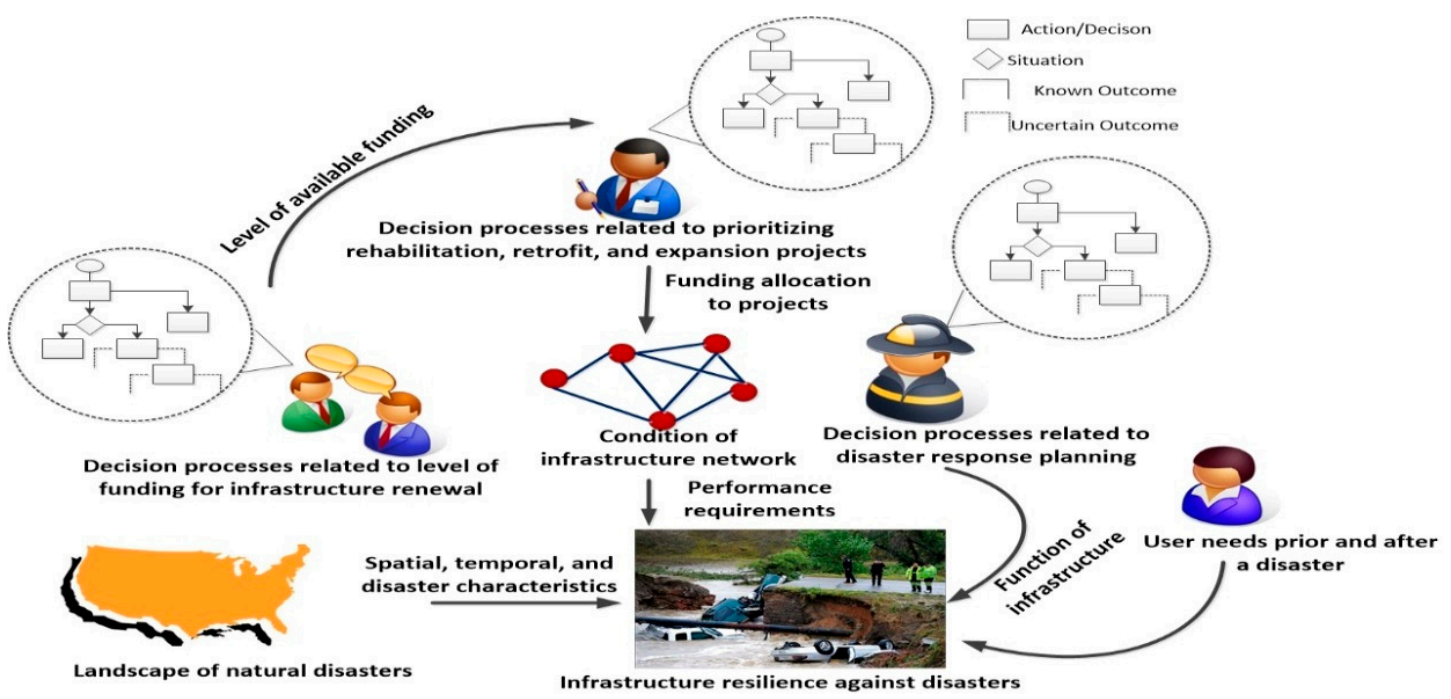

Figure 1. Infrastructure resilience: a system-of-systems problem.

Three dimensions can be investigated in a SoS approach for assessment of resilience in infrastructure systems (Figure 2). First, resilience analysis can be implemented with respect to different classifications in terms of infrastructure sectors, assets, performance condition, and natural hazards. Thus, the context of the analysis for this dimension is defined to include the classifications of sectors (e.g., transportation, water, power), assets (e.g., highways, roads, bridges, water mains), phases (e.g., preparedness, mitigation, response, and recovery), and natural disasters (e.g., hurricane, flood, earthquake). Resilience analysis could consider a single sector (tactical decision-making) or multiple sectors (strategic decision-making, where interdependencies are significant); or it may investigate a single asset (operational decision-making) or multiple assets (tactical decision-making). In addition, the analysis could consider the resilience of assets to one class or multiple classes of natural disasters. The greater the number of classifications considered, the greater the complexity of the analysis.

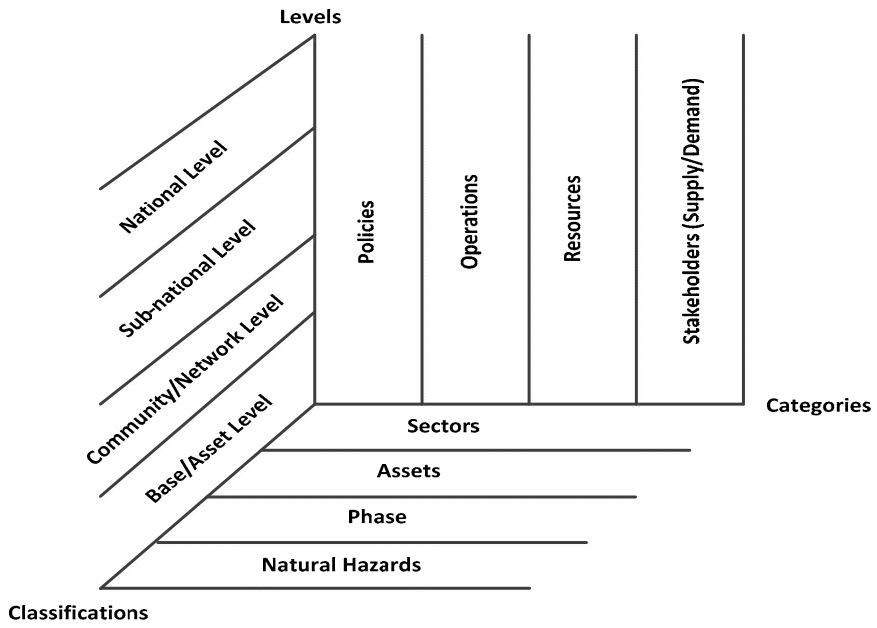

Figure 2. SoS approach for assessment of resilience in infrastructure.

In the second dimension of the proposed approach, different categories of components in the analysis are explored and abstracted. The component categories include resources, stakeholders, operations, and policies which exist across hierarchical levels. Resources include the non-human entities which facilitate rehabilitation, retrofit, and capacity expansion actions and could be physical or financial. Stakeholders are human and organizational entities whose goals, decision-making, actions, 
and interactions affect the planning and resource allocation of infrastructure. Operations include the application of the decisions/intents of stakeholders to direct the use of resources. Policies are external forces affecting the availability of resources and the decisions of stakeholders [24].

The third dimension pertains to the levels of analysis which include the asset, network, sub-national, and national levels. In the proposed SoS approach, the resilience at each level is obtained by aggregating the resilience at the level below it. This necessitates a definition of the resilience measures at each level. The multi-level aggregation of resilience in the proposed SoS approach enables the resilience of infrastructure systems to be integrated with the other dimensions of resilience (e.g., household and enterprise resilience) and combined into a regional resilience assessment as shown in Figure 3.

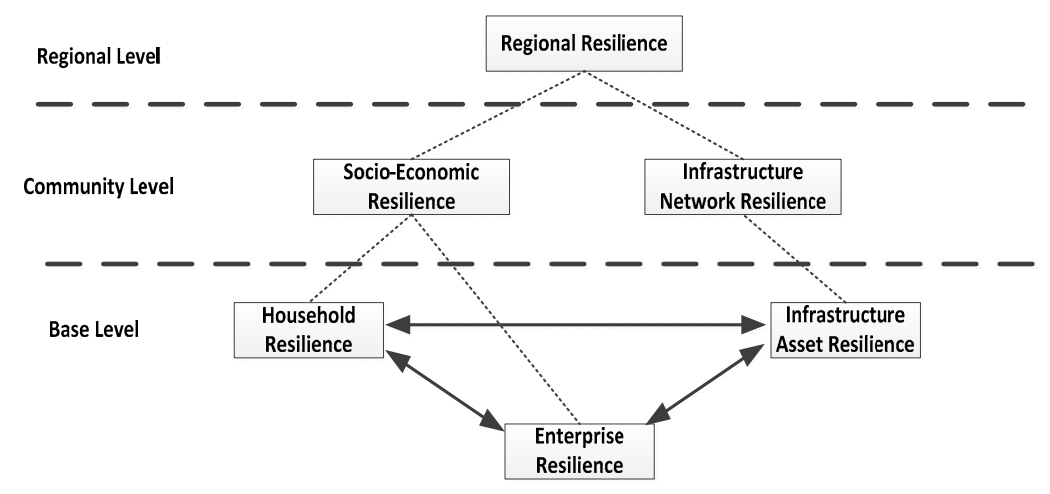

Figure 3. Multi-level aggregation of resilience.

\subsection{Resilience in Highway Transportation Infrastructure}

The proposed SoS approach provides a lens for an integrated assessment of resilience in infrastructure systems. The remaining sections of this paper demonstrate the application of the proposed SoS approach for investigation of the dynamics of resilience in highway transportation infrastructure systems in the U.S. using two case studies related to 2012 Hurricane Sandy and 2013 Colorado Floods. Table 1 summarizes the dimensions of analysis for using the proposed SoS approach in analysis of the case studies. The proposed SoS approach enables: (i) the boundaries of problems related to resilience analysis in infrastructure systems to be defined; (ii) the key stakeholders and their activities affecting the level of resilience to be abstracted and (iii) the status quo, drivers, and barriers for enhancing resilience in highway transportation infrastructure in the U.S to be investigated.

Table 1. Analysis of transportation infrastructure resilience using the SoS approach.

\begin{tabular}{|c|c|c|}
\hline Dimensions of SoS Approach & Components of Analysis & $\begin{array}{c}\text { Assessment of Resilience in Highway Transportation } \\
\text { Infrastructure }\end{array}$ \\
\hline Classifications & $\begin{array}{l}\text { Sectors } \\
\text { Assets } \\
\text { Phase } \\
\text { Natural hazards }\end{array}$ & $\begin{array}{c}\text { Highway transportation } \\
\text { Roads, highways, and bridges } \\
\text { Preparedness, mitigation, response, and recovery } \\
\text { Storm, hurricane, and flood }\end{array}$ \\
\hline \multirow{4}{*}{ Categories } & Resources & Capital and human resources \\
\hline & Stakeholders & $\begin{array}{l}\text { Public infrastructure and disaster management agencies, asset } \\
\text { owners and operators, private entities, MPOs, and engineering } \\
\text { and contracting companies }\end{array}$ \\
\hline & Operations & $\begin{array}{l}\text { Budget and resource allocation and prioritization of } \\
\text { rehabilitation and maintenance activities (pre- and post-disaster) }\end{array}$ \\
\hline & Policies & $\begin{array}{l}\text { Policies pertaining to operation and management of } \\
\text { transportation infrastructure }\end{array}$ \\
\hline Levels & $\begin{array}{l}\text { Base/Asset } \\
\text { Network } \\
\text { Sub-national }\end{array}$ & $\begin{array}{l}\text { Asset resilience } \\
\text { Network resilience } \\
\text { Regional resilience }\end{array}$ \\
\hline
\end{tabular}




\section{Data Collection and Analysis}

Information regarding the activities and interactions of different stakeholders related to two case studies of 2013 Colorado Floods and 2012 Hurricane Sandy is collected and analyzed using the proposed SoS approach to facilitate an integrated evaluation of transportation infrastructure resilience in the U.S. In depth interviews were conducted with different stakeholders (e.g., finance directors, transportation managers, emergency managers, urban planners, engineers, and city managers) at local, state and federal levels involved in preparedness planning, mitigation, response, and recovery efforts in the case studies. An initial list of the interviewees was compiled from an analysis of local and national agencies' websites and then the sample was expanded through snowball sampling. Table 2 summarizes the information related to the individuals that participated in the data collection interviews for these case studies.

Table 2. Participants in data collection interviews.

\begin{tabular}{ccc}
\hline Case Study & Agency & Number of Participants \\
\hline \multirow{3}{*}{ Colorado Flood } & Local Department of Public Works (Adams County) & 1 \\
& State Transportation Agency & 2 \\
& Federal transportation Agency & 2 \\
Hurricane Sandy & Consulting Firm & 3 \\
\hline \multirow{2}{*}{ State Transportation Agency } & 7 \\
\hline
\end{tabular}

The main purpose of the interviews was to understand the current practices pertaining to infrastructure asset management in the context of natural disasters. The interview instrument was semi-structured. It mainly included questions on the interviewees' professional backgrounds, involvement in select disasters, and the pre-and post-disaster transportation asset management and funding processes. The interviews were recorded with the permission of the participants and transcribed verbatim. The qualitative data collected from the case studies was coded and analyzed using NVivo 9 (NVivo qualitative data analysis Software, Version 10, QSR International Pty Ltd., Burlington, MA, USA) which allowed us to explore trends from the audio files and text. After analyzing the data from each case study site, a cross-case comparison was conducted to identify similar and contrasting patterns. The proposed SoS approach was used as the conceptual approach for interpreting the information collected from the case studies. In the remainder of this paper, the information collected from the interviews and proposed SoS approach are used to investigate the status quo, drivers, and barriers for enhancing resilience in transportation infrastructure systems. This information is then used to identify strategies for improving resilience in transportation infrastructure.

\subsection{Status Quo}

The status quo analysis highlights the activities of stakeholders related to four phases of resilience management: preparedness, mitigation, response, and recovery, and thus, enables the identification of the limitations of the existing practices and opportunities for improvement.

\subsubsection{Preparedness}

The preparedness component of infrastructure resilience focuses on all the processes related to dealing with natural disasters through a continuous cycle of planning, organizing, training, equipping, exercising, evaluating and taking corrective action. Based on the findings from the case studies, there are established procedures pertaining to disaster preparedness in federal, state, and local agencies dealing with transportation infrastructure. State transportation agencies have Incident Command Systems (ICS) under which the processes for disaster mitigation, response, and recovery are defined. However, the processes under ICS are mostly focused on issues such as rescue operation logistics and 
evacuation planning. In terms of infrastructure management, transportation agencies mainly evaluate the existing marterials with respect to their significance and capacity to support the evacuation and response activities. However, condition performance of transportation assets are not evaluated in preparedness planning. For both local and state transportation agencies, there is a disjoint between the asset and emergency management systems in terms of disaster preparedness. The condition assessment and performance measures in asset management systems are developed for business-as-usual/normal condition that may not consider the requirements under extreme events.

\subsubsection{Mitigation}

The mitigation component of infrastructure resilience focuses on understanding and reducing the vulnerabilities and exposure of infrastructure assets to natural disasters. The findings from the case studies revealed that there is no standard process for risk and vulnerability assessment in transportation infrastructure assets. Traditionally, the exposure of an infrastructure asset to disasters has been incorporated through design processes in which assets are engineered to withstand 20,50 or 100 year events (e.g., floods or earthquakes). However, the actual performance of infrastructure assets depend on their: (i) condition during the event; (ii) required functionalities during and after the event; and (iii) criticality for response and recovery. In addition, the existing methodologies for decision-making pertaining to transportation infrastructure assets has been based on some form of a cost-benefit analysis. However, most existing cost-benefit analyses do not incorporate the social, environmental, and economic losses associated with damages due to natural disasters. A robust risk and vulnerability assessment is critical in mitigation processes for transportation infrastructure in the context of natural disasters $[25,26]$. Other infrastructure sectors have already developed robust processes for risk and vulnerability assessment of their assets. For example, in the water sector, various utility companies have developed and used probabilistic risk and vulnerability models in their asset management systems. The findings from the case studies show that transportation agencies have realized the need for integrating risk and vulnerability assessment into asset management systems. For example, in the aftermath of Colorado Flood, Colorado Department of Transportation (DOT) initiated efforts to work with consulting companies with expertise in risk and vulnerability assessment to enhance the resilience of its infrastructure assets. The other critical component of mitigation processes is the availability of funding resources. The existing funding gap has led to delays in maintenance and rehabilitation activities for transportation infrastructure assets. For instance, a number of bridges had been identified with scouring issues prior the Colorado Floods; however, due to the funding constraints, maintenance and rehabilitation activities were delayed. The flood caused the scours to increase which led to the closure of the bridges. This also increased the repair cost associated with the extended damage.

\subsubsection{Response}

The response component of infrastructure resilience focuses on all the processes for evaluating the damages to the assets, the preliminary repair of the damaged assets, and the prioritization and allocation of the declared funding. Figure 4 summarizes the response process of transportation agencies.

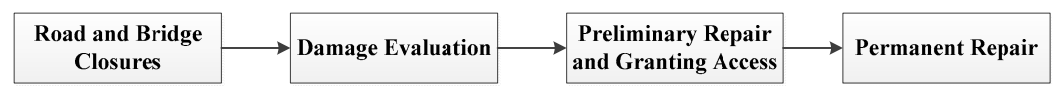

Figure 4. Transportation agencies' disaster response processes.

The Federal Emergency Management Agency (FEMA) coordinates the response efforts between different agencies in a temporary Joint Field Office (JFO) near the disaster zone. The evaluation of the damaged assets is mainly done by state and local transportation agencies as well as the Federal Highway Administration (FHWA). During the response activities, transportation agencies shift 
personnel from normal operations into emergency response roles. The primary goal of transportation agencies during the response phase is to provide access to the affected communities by performing preliminary repair to damaged assets. The majority of permanent repairs are implemented during the recovery phase. During the response phase, the goal could be to maximize the amount of temporary repairs that will be deemed suitable for permanent use. For example, in the aftermath of the 2013 Colorado Floods, Colorado DOT was able to convert over $80 \%$ of their temporary repairs into permanent repairs through as-built engineering analyses.

\subsubsection{Recovery}

The recovery component of transportation infrastructure resilience focuses on providing major retrofit and rehabilitation to the damaged transportation assets. The retrofit/rehabilitation projects are initially funded by local and state agencies while they wait to receive the Federal disaster aid. The allocation of federal disaster relief funds to projects is made based on the damage evaluations made by local and state transportation agencies (STA) under FHWA oversight. State and local transportation agencies prepare initial estimates and repair scope packages. The federal disaster relief funds are only allocated to the damages caused by the disaster. For instance, if a bridge had significant scouring prior to the event which was worsened due to the event, the emergency funding will only cover that which is attributable to the disaster. During the recovery phase, state and local transportation agencies adopt a two phase approach to repair the damaged assets. First, the asset is repaired to its pre-disaster performance standard. Then, additional improvements may be made to enhance the resilience against future disasters. This additional improvement (so called "betterment process") is made from the portion of the federal disaster relief funds. The repair and betterment projects are implemented using normal delivery processes. In the aftermath of a disaster, there is distinct desire in transportation agencies to bolster resiliency (a "never again" attitude emerges). The transportation agencies in Colorado and New York have developed initiatives and processes to enhance the resilience of transportation during the recovery process. However, these processes and measures are taken with the almost inevitable attitude that funding priorities, political climate or other external factors will ultimately derail these best-laid plans.

\subsection{Drivers}

The increased frequency and severity of natural disasters is the main driver for operationalizing resilience in transportation infrastructure systems. The severity of damages to transportation infrastructure during the recent natural disasters has been significant. For example, in August 2011, "Hurricane Irene reached one of the nation's most northern states, Vermont, and damaged 480 bridges out of a total network of 2717 bridges. In one day, more bridge deterioration occurred than normally would occur over many years" [27]. The damages to infrastructure systems could affect public safety, business continuity of private enterprises, and response operations. These impacts could raise political, community, and private sector pressures on the transportation agencies to enhance the resilience of transportation infrastructure. These pressures increase the likelihood of support from the executive teams in the transportation agencies to start or reinforce initiatives that foster resilience in transportation networks.

Another driver for operationalizing resilience is guidance from the USDOT and FHWA. Since these organizations act in a supervisory capacity and have been involved with disasters across state lines, they have insight into the strategies that have proven successful. Hence, the role of federal agencies to provide guidelines and disseminate the best practices pertaining to enhancing the resilience of infrastructure systems is critical. Ultimately, each transportation agency is most responsible for operationalizing resilience to match their unique needs, organizational priorities, and infrastructure characteristics. These elements determine what strategies could be effective for each agency and what insight from the other agencies or from the national level could help. 


\subsection{Barriers}

Persistent funding constraints is the major barrier to fostering resilience in transportation infrastructure. As shown in Figure 5, the existing funding constraints could affect the efficiency of funding allocation. Due to funding constraints, the maintenance, rehabilitation, and retrofit activities might be postponed. Postponing the improvement of infrastructure assets can lead to more severe damages when a natural disaster happens. For example, during the Colorado Floods in 2013, one bridge in Adams County experienced severe damage due to scouring. The need for repairing the bridge had been identified a few years before the flood; however, the existing funding constraints prevented any repair or retrofit activities from being implemented. Fortunately for Adams County, they were impacted significantly less by the flood compared to Boulder and Larimer Counties. This illustrates the effects that funding constraints can have on communities even when the damage is relatively minor.

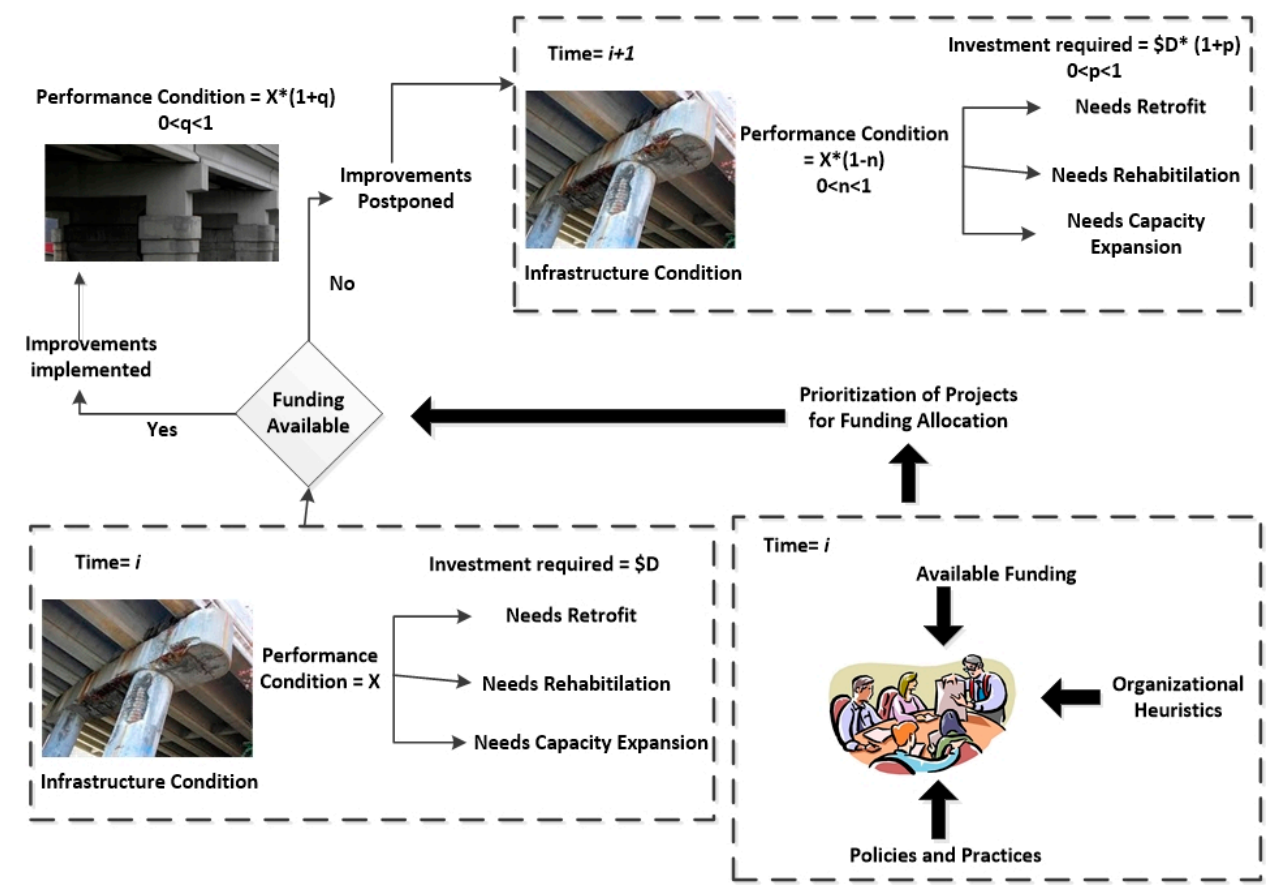

Figure 5. Impact of funding constraint on prioritization of maintenance/retrofit activities.

The second barrier towards operationalizing resilience is the lack of established approaches for evaluating the vulnerability and exposure of assets and networks to natural disasters. This limitation affects the efficiency of funding allocation to improvement and betterment projects. An established approach for assessment of asset vulnerability and exposure requires risks to be incorporated and performance measures be developed to objectively evaluate the level of resilience under different uncertain scenarios. An example of such an approach is the method proposed by Meyer [26] for assessment of vulnerability and exposure in management of transportation infrastructure assets.

The third barrier to operationalizing resilience in transportation infrastructure is the internal resistance to change in transportation agencies. Fostering resilience requires integration of the efforts across different units (e.g., planning, design, construction, operation, and asset management) and entails changes in the current practices pertaining to the operation and management of infrastructure. Resistance to change is natural in large organizations, especially when the need for change is uncertain. The uncertainty in the occurrence of disasters reduces the urgency of the need for improving resilience. However, in the aftermath of a disaster, there is distinct desire in transportation agencies to bolster resiliency (a "never again" attitude emerges). The transportation agencies in New York and Colorado that experienced these destructive disasters have developed initiatives and processes to enhance the 
resilience of transportation during the recovery process. For New York in particular, Hurricane Irene in 2011 was the wakeup call with Hurricane Sandy as the second alarm.

Finally, the limitation of data and lack of indices for evaluating the resilience of transportation assets and networks is another barrier. Use of resilience indices is critical in investigating baseline condition in policy assessment and decision-making in the context of disasters [28]. The transportation agencies need to define specific guidelines pertaining to the data required for development of resilience indices in transportation assets and networks. In order to integrate decision-making processes across asset and network levels, the resilience indices should be developed based on accurate data pertaining to the condition and criticality of assets and likelihood and severity of disasters.

\section{Strategies for Improvement}

According to the information collected from the interviews, three interrelated strategies have been identified to foster operationalizing resilience in management of transportation infrastructure systems.

\subsection{Expanding the Available Funding for Retrofit and Betterment Projects}

In many transportation agencies, one of the barriers towards enhancing the resilience of transportation infrastructure is the limitation of funding resources. However, our survey findings reveal that increasing the level of funding may not necessarily lead to an enhanced level of resilience. In order to prioritize projects based on their contribution to the resilience of transportation infrastructure, there is a need for a special vehicle funding source. A resilience-enhancing funding source would require the transportation agencies to objectively evaluate the resilience of their assets to justify the need for funding. Such a funding resource would prevent postponing retrofit and rehabilitation activities that might not be otherwise implemented. For example, a slope armoring project might not be considered as a priority project unless there are objective approaches for evaluating the significance of the project to resilience measures and there are available funding resources to finance the project.

\subsection{Use of Risk and Vulnerability Assessment in Conjunction with Resilience Indices}

The existing asset management systems in transportation agencies do not consider the risks and vulnerabilities related to natural disasters. The transportation asset management systems are mainly focused on the required performance measures under normal conditions. One solution to operationalize resilience into transportation asset management practices is the development and use of probabilistic risk and vulnerability analysis and its integration with the existing business processes (e.g., long term planning, programming, corridor planning, and operation) in transportation agencies. The outcome of such integrated resilience assessment will include resilience indices at asset and network levels for evaluation of planning and decision strategies during each business process. Use of resilience indices is critical in investigating baseline condition in policy assessment and decision-making in the context of disasters [28]. Different studies have proposed resilience indices for physical networks (e.g., [29]), communities (e.g., [30]), and regions (e.g., [12]).

\subsection{Integration of the Efforts across Different Players and Units}

The survey analysis reveals that the activities of different local, state, and federal agencies are disjointed except during the response phase. During the response phase, different agencies work together at the FEMA-run Joint Field Office (JFO) to expedite and enhance the response efforts. Once the response phase is over, FEMA closes the JFO-the component that utilized the most cooperation and had the biggest positive impact. Such an integrated effort needs to be extended to preparedness, mitigation, and recovery phases. The local, state, and federal transportation agencies along with FEMA can define and monitor acceptable threshold values for transportation infrastructure assets and continuously plan to reduce the vulnerability and exposure of transportation assets to natural disasters during all business processes. The integration of efforts should also be expanded across different units 
(e.g., planning, design, construction, and operation) within transportation agencies. An integrated effort could lead to better understanding of vulnerabilities and risks across different phases in the lifecycle of transportation assets.

\section{Conclusions}

This paper presented the dimensions of analysis and determinants of resilience in transportation infrastructure using a systems-of-systems approach. The application of the proposed approach was shown in a preliminary assessment of resilience in transportation infrastructure using the information collected from case studies related to 2012 Super Storm Sandy and the 2013 Colorado Floods. The case studies investigate the interconnections between the decision-making of actors related to prioritization of funding allocation, condition of infrastructure, and the level of resilience. The results showed that the major focus of transportation agencies is on evacuation and response planning and post-disaster damage assessment and repair. There is a disjoint between the activities of transportation agencies pertaining to pre-disaster assessment of vulnerability and exposure, as well as pre-disaster improvements and betterment efforts. The results also highlighted the role of federal agencies for providing guidance on identifying and implementing the best practices related to enhancing resilience in transportation systems. Based on the results of the analysis, the drivers and barriers for enhancing resilience in transportation infrastructure systems were identified. The major drivers for enhancing resilience include: availability of funding, integration of efforts across different units in the organization, use of risk and vulnerability approaches, and use of resilience indices for decision-making. Their implementation could ultimately lead to improvement of public safety and a reduction in the financial burden caused when natural disasters occur.

The approach proposed in this study can integrate the decision-making processes of different players pertaining to resource allocation for rehabilitation, capacity expansion, and retrofit actions with the condition of infrastructure assets and their resilience against natural disasters at the asset, network, sub-national, and national levels. The proposed approach can provide a bottom-up approach for resilience-based planning and potentially assist decision-makers in the following areas: (i) prioritization of infrastructure renewal activities for resource allocation; (ii) investigation of the impacts of resource constraints on the level of resilience in infrastructure systems at the sub-national and national levels; and (iii) evaluation of the landscapes of sustainable strategies to enhance the resilience of infrastructure.

Conflicts of Interest: The author declares no conflict of interest.

\section{References}

1. Hewitt, K. (Ed.) Interpretations of Calamity; Allen and Unwin: Boston, MA, USA, 1983.

2. White, G.F. Human Adjustment to Floods; The University of Chicago: Chicago, IL, USA, 1945.

3. Holling, C.S. Resilience and stability of ecological systems. Annu. Rev. Ecol. Syst. 1973, 4, 1-23. [CrossRef]

4. Manyena, S.B.; Fordham, M.; Collins, A. Disaster resilience and children: Managing food security in Zimbabwe's Binga district. Child. Youth Environ. 2008, 18, 303-331.

5. Peek, L. Children and disasters: Understanding vulnerability, developing capacities, and promoting resilience-An Introduction. Child. Youth Environ. 2008, 18, 1-29.

6. Ronan, K.R.; Crellin, K.; Johnston, D.M.; Becker, J.; Finnis, K.; Paton, D. Promoting child and family resilience to disasters: Effects, interventions and prevention effectiveness. Child. Youth Environ. 2008, 18, 332-353.

7. Berke, P.R.; Campanella, T.J. Planning for Post-disaster Resiliency. Ann. Am. Acad. Political Soc. Sci. 2006, 604, 192-207. [CrossRef]

8. Campanela, T.J. Urban Resilience and the Recovery of New Orleans. J. Am. Plan. Assoc. 2006, 72, 141-146. [CrossRef]

9. Vale, L.; Campanella, T.J. (Eds.) The Resilient City: How Modern Cities Recover from Disaster; Oxford University Press: New York, NY, USA, 2005.

10. Mileti, D.S. Disasters by Design: A Reassessment of Natural Hazards in the United States; National Academies Press: Washington, DC, USA, 1999. 
11. Mayunga, J.S. Understanding and applying the concept of community disaster resilience: A capital-based approach. In Proceedings of the Summer Academy for Social Vulnerability and Resilience Building, Munich, Germany, 22-28 July 2007; pp. 1-16.

12. Cutter, S.L.; Burton, C.G.; Emrich, C.T. Disaster resilience indicators for benchmarking baseline conditions. J. Homel. Secur. Emerg. Manag. 2010, 7. [CrossRef]

13. Batouli, M.; Mostafav, A. Service and performance adjusted life cycle assessment: A methodology for dynamic assessment of environmental impacts in infrastructure systems. Sustain. Resil. Infrastruct. 2017, 2, 117-135. [CrossRef]

14. Azevedo de Azevedo, B.; Mostafavi, A. Resilience of Infrastructure Systems to Sea-Level Rise in Coastal Areas: Impacts, Adaptation Measures, and Implementation Challenges. Sustainability 2016, 8, 1115. [CrossRef]

15. Faturechi, R.; Miller-Hooks, E. A mathematical approach for quantifying and optimizing protective actions for civil infrastructure systems. Comput. Aided Civ. Infrastruct. Eng. 2014, 29, 572-589.

16. Rinaldi, S.M.; Peerenboom, J.P.; Kelly, T.K. Identifying, understanding, and analyzing critical infrastructure interdependencies. IEEE Control Syst. 2001, 21, 11-25. [CrossRef]

17. O'Rourke, T.D. Critical infrastructure, interdependencies, and resilience. In The Bridge; National Academy of Engineering-Spring: Washington, DC, USA, 2007; pp. 22-29.

18. Reed, D.A.; Kapur, K.C.; Christie, R.D. Methodology for assessing the resilience of networked infrastructure. IEEE Syst. J. 2009, 3, 174-180. [CrossRef]

19. DeLaurentis, D.A. A taxonomy-based perspective for systems of systems design methods. In Proceedings of the 2005 IEEE International Conference on Systems, Man and Cybernetics, Waikoloa, HI, USA, 12 October 2005; Volume 1, pp. 86-91.

20. Maier, M.W. Architecting principles for systems-of-systems. Syst. Eng. 1998, 1, 267-284. [CrossRef]

21. Zhu, J.; Mostafavi, A. Integrated Performance Assessment in Complex Engineering Projects Using a Systems-of-Systems Approach. IEEE Syst. J. 2017, PP, 1-12. [CrossRef]

22. Mostafavi, A.; Abraham, D.M.; DeLaurentis, D.; Sinfield, J. Exploring the dimensions of systems of innovation analysis: A system of systems approach. IEEE Syst. J. 2011, 5, 256-265. [CrossRef]

23. Mostafavi, A.; Abraham, D.M.; Lee, J. System-of-Systems Approach for Assessment of Financial Innovations in Infrastructure. J. Build. Environ. Proj. Asset Manag. 2012, 2, 250-265. [CrossRef]

24. Mostafavi, A.; Abraham, D.; DeLaurentis, D.; Sinfield, J.; Kandil, A.; Queiroz, C. Agent-Based Simulation Model for Assessment of Financing Scenarios in Highway Transportation Infrastructure Systems. J. Comput. Civ. Eng. 2015, 30. [CrossRef]

25. Meyer, M.; Flood, M.; Keller, J.; Lennon, J.; McVoy, J.; Dorney, C.; Leonard, K.; Hyman, R.; Smith, J. Climate Change, Extreme Weather Events and the Highway System: A Practitioner's Guide; National Cooperative Highway Program, Transportation Research Board: Washington, DC, USA, 2014.

26. Meyer, M.; Rowan, E.; Savonis, M.; Choate, A.; ICF International. Integrating Extreme Event Risk in Transportation Asset Management; American Association of State Highway and Transportation Officials: Washington, DC, USA, 2013.

27. Federal Highway Administration (FHWA). Risk-Based Transportation Asset Management: Building Resilience into Transportation Infrastructure. 2013. Available online: http:/ / www.fhwa.dot.gov/asset/ pubs / hif13018.pdf (accessed on 4 April 2014).

28. Tierney, K.; Bruneau, M. Conceptualizing and measuring resilience: A key to disaster loss reduction. TR News 2007, 17, 14-15.

29. Mostafavi, A.; Inman, A. Exploratory analysis of the pathway towards operationalizing resilience in transportation infrastructure management. Built Environ. Proj. Asset Manag. 2016, 6, 106-118. [CrossRef]

30. Mostafavi, A.; Abraham, D.M. Resilience-Based Planning in Civil Infrastructure using System-of-Systems Analysis. In Proceedings of the ASCE Construction Research Congress 2014, Atlanta, GA, USA, 19-21 May 2014.

(C) 2017 by the author. Licensee MDPI, Basel, Switzerland. This article is an open access article distributed under the terms and conditions of the Creative Commons Attribution (CC BY) license (http:/ / creativecommons.org/licenses/by/4.0/). 